\title{
Is it love or loneliness? Exploring the impact of everyday digital technology use on the wellbeing of older adults
}

\author{
CAROLYN WILSON*
}

\begin{abstract}
Loneliness is a prevalent phenomenon within the older adult population. Previous literature suggests that technology use, specifically internet use, can alleviate loneliness and improve wellbeing. This research study follows 32 people over the age of $6_{5}$ using a digital technology for six months. A mixed-method approach was used to collect quantitative and qualitative data throughout the time period. The repeated questionnaire measured changes in frequency of use, emotional attachment towards a device, a sense of belonging and perceptions of self-worth, whilst an event-based diary was used to note usages and influences of technology on lifestyle. Results revealed positive relationships between frequency of use and emotional attachment and frequency of use and perceptions of self-worth. There was no significant relationship between frequency of use and a sense of belonging for the aggregate data. There was, however, a negative relationship between emotional attachment towards a device and a sense of belonging, suggesting a fine balance between technology use to improve self-esteem through connections with social networks and an over-dependence on technology that can actually reduce feelings of belonging.
\end{abstract}

KEY WORDS - older adults, loneliness, wellbeing, digital technology.

\section{Introduction}

In the 2011 United Kingdom (UK) census it was revealed that one-sixth of the population (16.4 per cent) were over the age of $6_{5}$, recording the highest proportion of older adults in census history (Office for National Statistics 2012). This figure is continuing to increase as baby-boomers from the 195 os population surge into the older adult category. The rapid growth of the ageing population has placed great strain on the National Health System (NHS) with 65 per cent of hospital admissions comprised of older adults, accounting for almost 70 per cent of hospital emergency bed days

* Durham University Business School, Durham University, UK. 
(Imison, Thompson, and Poteliakhoff 2012). Moreover, once older adults are admitted to hospital, they often stay longer and are more likely to be re-admitted (Cornwell et al. 2012). It is often assumed that this strain on the NHS is due to physical ailments, however, the impact that mental health has on care systems and the individual is also important (Porock et al. 2015). In 2005, 6o per cent of the older people admitted to hospital developed a co-morbid mental disorder during their hospitalisation: $3^{1}$ per cent developed dementia, 29 per cent suffered from depression and 20 per cent were subject to delirium (Royal College of Psychiatrists 2005). In addition, the care of these patients and their conditions has been reported as poor (Tadd et al. 2011 ), due to a lack of understanding of mental health in older adults.

One of the most prominent mental conditions inherent in the ageing process is loneliness; a subjective and frequently painful and troubling feeling of being emotionally and/or socially isolated (Weiss 1973). Often literature uses the term loneliness in conjunction with other concepts such as 'living alone', 'being alone' and 'social isolation' (Victor et al. 2005: 358). However, being physically alone does not necessarily mean that somebody is lonely and being with somebody does not always prevent loneliness (Kirkevold et al. 2012). Academic research surrounding loneliness in older people demonstrates that approximately 40 per cent of people over the age of 65 will admit to being lonely (Savikko et al. 2005; Steed et al. 2007; Victor et al. 2005). The percentage of people suffering from loneliness is higher in people aged 80 or older (Dykstra, Van Tilburg and de Jong Gierveld 2005; Jylha 2004; Savikko et al. 2005) and people living on their own (Kharicha et al. 2007).

The foremost cause of loneliness is the death of friends and relatives experienced in later life (Kirkevold et al. 2012). It is also believed that another prominent cause is health degradation; as poor health increases with age it leads to a higher risk of social loneliness. This is especially true when health reasons prevent people from partaking in social and leisure activities (Scherger, Nazroo and Higgs 2010). Health status can be both a predictor and consequence of loneliness, in that mobility problems and physical disabilities can cause people to interact less hence increasing their loneliness, whilst an increased loneliness can cause depression (Van Beljouw et al. 2014), alter sleep patterns and appetite (Drennan et al. 2008), which in turn creates further health degradation. Victor and Bowling (2012) suggest that, as well as social interaction schemes, the treatment of chronic and long-term health conditions would also have a huge impact on improving this issue.

There are many proposed solutions to avoiding loneliness and its effects, with the most effective involving educational interventions that focus on maintaining social networks (Cohen-Mansfield and Perach 2015). An 
example of this is a study by Savikko et al. (2005), which indicates that group activities in art, exercise, therapeutic writing and group therapy have positive effects on reducing feelings of loneliness amongst people aged 75 and over. Gaymu and Springer (2010) evidence that engaging in such social activities correlates positively with life satisfaction and, as a result, these activities should be encouraged for both men and women. Heylen (2010) concurs and suggests that people should attach great importance to both quality and quantity of their social networks. Consequently, one way to reduce loneliness is to improve connections between older adults and their social network, despite geographical and health obstacles (Drennan et al. 2008), which can be achieved through the use of digital technology.

Literature on older adults' use of technology, specifically ICT (information and communications technology), computer and internet use, started to become a prevalent topic in 1994. As the older population grows, the research surrounding technology use by this age group is also expanding. The two disciplines with the most journal publications on this topic are gerontology with $4^{0}$ and human-computer interaction with $5^{6}$ between 1994 and 20o8. Over time, business studies and health-care research are also paying increasing attention to the issue of computer use by older adults whilst, on the other hand, psychology and education have produced few publications on the topic (Wagner, Hassanein and Head 2010). The present paper expands the research in the business studies discipline, focusing primarily on consumer behaviour from a radical behaviourist perspective. Moreover, being a relatively new area of interest, there are certain topics of focus and remaining issues requiring further scholarship, which this paper wishes to address.

Recent studies have demonstrated the impact that technology can have on feelings of loneliness, for instance telephone befriending schemes have helped older people gain confidence and a sense of belonging (Cattan, Kime and Bagnall 2011) whilst the internet has provided the functionality to improve feelings of being alone (Karavidas, Lim and Katsikas 2005; Sum et al. 2008). Ballantyne et al. (2010) discovered that older adults participating in a social networking website had the potential to reduce feelings of loneliness. They argue, however, for further investigation into this phenomenon as current literature often assumes the benefits of technology on older adults' quality of life. Consequently, much literature analyses how computer use can be learned (Buse 2010; Lam and Lee 20o6) or whether age affects the ability to use a device (Arning and Ziefle 2007, 2009; Chevalier, Dommes and Matins 2013; Mata and Nunes 2010; Nägle and Schmidt 2012), in an attempt to suggest ways of teaching technology consumption to this population. 


\section{Carolyn Wilson}

Actual usage has been recorded to some degree with descriptions of what technology is used for, e.g. communication and social support (Thayer and Ray 2006) and information searching (Rosenthal 2008), however the recording of frequency of usage in relation to outcome measures is limited. According to Wagner, Hassanein and Head (2010), this is because the majority of studies on older adults' use of technology are cross-sectional and only record a snippet of information at one single point in time. There is subsequently a strong argument for further longitudinal and cross-sectional studies on technology use by this age group. A few longitudinal studies have been successful at indicating internet usage by older adults for everyday uses (Hedman et al. 2013; Lam and Lee 2006) or specific purposes such as searching for health information (Flynn, Smith and Freese 2006) or maintaining social connections (Berkowsky et al. 2013). For the majority of these publications, the older adult participants are generally between the ages of 55 and $6_{5}$. As a result, further longitudinal research is required on people over the age of $6_{5}$ and their use of technology.

Finally, the majority of literature that identifies older adults as technology users often focuses on general ICT such as computer and internet use (Wagner, Hassanein and Head 2010). As previously indicated, these studies commonly investigate the influence of age on usage and technical performances, alongside attitudes towards ICT. Literature that does explore the use of more specific technologies in the context of older adults often investigates assistive technologies such as robotics (Heerink et al. 2008) and in-home monitoring (Mortenson et al. 2012; Poland et al. 2011; Wild et al. 2008). Investigation into everyday technologies is limited, with the exception of the mobile phone literature (Hardill and Olphert 2012; Joe and Demiris 2013; Lee 2007). Considering that everyday digital technologies such as mobile phones, tablets, laptops and e-readers take such an important part in our lives, we must strive to decipher how older adults interact with these technologies and whether they can actually improve loneliness and wellbeing.

This paper addresses the gaps in the literature, firstly, by exploring the relationships that older adults have with everyday digital technologies such as smartphones, e-readers, tablets and laptops; secondly, by exploring whether the use of technology can impact upon older adults' feelings of loneliness and wellbeing. Finally, being a study across a six-month period, it intends to add to the literature on older adult technology use across time by recording frequency of usage against several outcome measures such as emotional attachment towards a device, a sense of belonging and perceptions of self-worth. Moreover, as technology is constantly evolving, this study provides a current exploration of modern technologies by an older adult population that have used ICT professionally or leisurely. 


\section{Methodology}

\section{Outcome measures}

To measure the extent to which older adults were using their everyday device and the relationship that they had with technology, frequency of use was recorded alongside the outcome measure of emotional attachment towards the device. The idea of measuring emotional attachment arose from attachment theory (Ainsworth 1979; Bowlby 1969), which was initially developed to comprehend the relationship between infant and care-giver. It conceptualises attachment as an infant's inherent, goal-corrected control system that regulates his or her behaviours to create or maintain closeness to a particular care-giver or attachment figure. Through this, the infant secures their protection from psychological and physical threats whilst discovering emotion regulation and healthy exploration (Bowlby 1969).

Recent psychology and marketing literature has indicated that attachments go beyond relationships between people to relationships between people and retailers (Vlachos et al. 2010), brands (Carroll and Ahuvia 2006), firms (Yim, Tse and Chan 2008), places (Morgan 2010) and material possessions. Material possessions have included portable devices, especially mobile phones (Vincent 2006). The primary findings indicate that people interact with portable devices in an emotional way, at a personal and social level. Consumers have an attachment to both the device and the information stored on it, indicating at times an over-dependence on the technology (Vincent 2006).

There are qualitative studies that briefly refer to the emotional connection that older people have with certain new technologies but these studies are predominantly focused on specific devices such as electric scooters that provide freedom and autonomy (May, Garrett and Ballantyne 2010) or interactive care robots that are enjoyable to use (Heerink et al. 2008; Wada and Shibata 2007). To decipher the extent to which older adults are using technology, it important to see if older adults develop the same emotional attachment towards their devices and if this outcome can be quantified using an emotional attachment scale by Ball and Tasaki (1992).

To measure the loneliness and wellbeing of the participants, two measures were chosen: a sense of belonging metric (Hagerty and Patusky 1995) and a scale of self-esteem (Rosenberg 1989). Moreover, much of the literature suggests social interaction and group activities as effective solutions to alleviating loneliness (Kirkevold et al. 2012). As such, the present study plans to use a sense of belonging scale, which identifies whether a person feels they belong within the world, to see the effects of technology use on loneliness. Self-esteem has been chosen as the second 


\section{Carolyn Wilson}

metric because it can be enhanced by reducing loneliness, increasing independence, improving social connections and enhancing learning; all of which can be achieved through the use of technology. From previous literature on assistive technologies, devices must increase functional ability and older adults' perceptions of self-worth (Hirsch et al. 200o) in order to improve the older adult's physical and social wellbeing.

\section{Data collection and analysis}

Emerging from a radical behaviourist perspective, the methodology adopted a pragmatic positivist approach and, as such, quantitative methods are prioritised as they allow observations and measurements to be made objectively; however, the theory also encourages qualitative methods where quantitative measurements prove impractical or impossible. These qualitative methods do, however, have to generate an explanation of behaviour that is independent from the results of the quantitative research and be interpreted by an independent researcher (Foxall 1995, 1998). Consequently, a mixed-methods approach was adopted for the data collection and analysis, enabling a rich collection of data across a six-month period.

The sample of 32 older people was recruited from University of the Third Age $\left(\mathrm{U}_{3} \mathrm{~A}\right)$ organisations across the UK, through newsletters, websites and e-mails. The recruited participants were from the following areas, providing a range of rural and urban locations: Chiltern, Carrick, Malvern, Aylesbury, London, Maidenhead, Bath, Cambridge, Thame, Chesterfield, Harrogate, Cheadle Hulme and Long Eaton. Each participant was over the age of $6_{5}$, living in the UK and had acquired a new technology in the 12 months prior to the start of the study. There were 21 females $(65.6$ per cent) and 11 males ( 34.4 per cent); ages ranged from 65 to 88 years, equating to an average age of $77 ; 23$ of the participants were married and living with their spouse (71.9 per cent), four were widowed (12.5 per cent), three were divorced ( 9.4 per cent) and two never married (6.3 per cent). The education of the participants varied with two uneducated (6.3 per cent), six educated to school level ( 18.8 per cent), 11 with a professional accreditation (34.4 per cent), six with an undergraduate degree ( 18.8 per cent) and seven with a postgraduate degree (21.9 per cent). The participants were also using a variation of everyday digital technologies that included one brain trainer, one smart TV, six smartphones, seven laptops, eight ereaders and nine tablets.

To collect data for the quantitative analysis, participants were asked to complete a survey once a month for a period of six months; the survey used psychological scales and socio-economic measures to record changes in older adults' technology use. Outcomes that were measured include 
frequency of use, emotional attachment towards the device, sense of belonging and perceptions of self-worth. Frequency of use was a self-reported value to the question 'How many times have you used your [insert device] in the past month?' Emotional attachment towards a technology was recorded using Ball and Tasaki's (1992) measure of attachment in consumer psychology: a nine-item, six-point Likert scale. Sense of belonging was measured using Hagerty and Patusky's (1995) sense of belonging metric: an 18-item, four-point Likert scale. Finally, the Rosenberg (1989) scale of self-esteem was chosen to measure perceptions of self-worth: a ten-item, four-point Likert scale. As the study was six months long, 29 of the 32-participant sample were able to complete all of the six surveys, giving a total 174 completed responses across six months. The aggregate data also include surveys completed within a shorter time period providing 188 responses from the 32 participants.

The survey data were analysed quantitatively using SPSS. Pearson product moment correlations were applied to the aggregate data to explore relationships between frequency of use, emotional attachment, sense of belonging and perceptions of self-worth. The data collated over six months were used to divide the participants into three groups: those whose usage increased over the six months, those whose usage decreased and those whose usage remained constant (see Table 2). The three usage groups were constructed to see if there was an impact of frequency of use on emotional attachment towards a device, a sense of belonging and perceptions of self-worth. An unrelated one-way analysis of variance (ANOVA) was utilised for each of the outcome measures to see if there was a significant difference between the usage groups and what impact rate of usage had on each of the measures.

The qualitative data collection was also over a six-month period; participants were encouraged to write in their diary regarding usage of their technology and asked to note down any influences there may be that either increased or decreased their technology use. These are often called eventbased diaries (Bolger, Davis and Rafaeli 2003) or event-contingent protocols (Wheeler and Reis 1991) and have been used in previous post-purchase consumption studies (Zarantonello and Luomala 2011). Participants were given the freedom to use any format of diary that they felt comfortable with, which produced data that were open and expansive. The majority of people, however, chose to type their diaries in a Word document, which in itself reflects a competence and use of technology (Bolger, Davis and Rafaeli 2003). Due to a level of autonomy with the format, the diaries

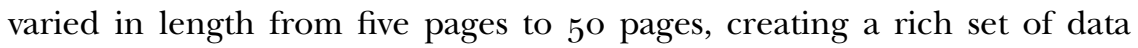
that was analysed using content analysis.

The event-based diaries were coded thematically, based on the outcome measures explored in the present paper. Each outcome measure had two 


\section{Carolyn Wilson}

separate themes: a positive and a negative. For instance, an account of a positive emotional attachment towards a device included the user developing positive emotions, a bond and/or feelings of protection towards the technology. Alternatively, negative emotional attachment towards a device included only associating negative emotions with it, such as anger, frustration and resentment, demonstrating no connection to the technology and an apathy about the future of the device. A coding guide was established, which allowed the diary data to be analysed in a systematic manner and by two separate researchers (Millward 2006). After this procedure, there was an agreement percentage of 89.91 per cent across the 1,034 different observations. Alongside this measurement, a Cohen's kappa (Cohen 1960) was used to indicate the reliability of the coding. The calculated kappa of the coded data was 0.693 , which indicated that the reliability of the data observations is substantial (Landis and Koch 1977). There are debates about the magnitude guidelines and the significance of the kappa value but considering that any value over 0.75 is classed as excellent and over 0.81 as near perfect agreement (Landis and Koch 1977), the present example stands as adequately statistically significant. The coding was developed to support the quantitative data and provide context to the findings. Additionally, a frequency word search was used from which subthemes emerged explaining the relationships between variables and providing answers to behaviour.

\section{Findings and discussion}

\section{Statistical analysis}

How often the technological device was used each month was recorded by the participants and subsequently compared to the three other outcome measures. The aggregate data, in Table 1 , reveal positive relationships between frequency of use and emotional attachment $(r=0.221, p=0.002)$ and frequency of use and perceptions of self-worth $(r=0.261, p=0.000)$ but no relationship between frequency of use and sense of belonging $(r=0.099, p=0.177)$. Other relationships include a positive correlation between sense of belonging and perceptions of self-worth $(r=0.733$, $p=0.000)$ and negative relationships between emotional attachment to a device and sense of belonging $(r=-0.376, p=0.000)$ and emotional attachment to a device and perceptions of self-worth $(r=-0.170, p=0.000)$.

For emotional attachment, the assumption of homogeneity of variance was violated and as such the Welch F-ratio is reported. There is a significant effect of technology usage on emotional attachment towards the device, $F(2,113.59)=13.39, \quad p=0.000$. A Games-Howell post-hoc test reveals 
TAB LE 1. Pearson correlations between frequency of use (FU), emotional attachment (EA), sense of belonging (SB) and perceptions of self-worth (PSW)

\begin{tabular}{llllll}
\hline & FU & EA & SB & PSW & \\
\hline FU & Pearson correlation & 1 & $0.221^{* *}$ & 0.099 & $0.261^{* *}$ \\
& Significance (two-tailed) & & 0.002 & 0.177 & 0.000 \\
& N & 188 & 188 & 188 & 188 \\
EA & Pearson correlation & $0.221^{* *}$ & 1 & $-0.36^{* *}$ & $-0.10^{*}$ \\
& Significance (two-tailed) & 0.002 & & 0.000 & 0.020 \\
& N & 188 & 188 & 188 & 188 \\
SB & Pearson correlation & 0.099 & $-0.376^{* *}$ & 1 & $0.733^{* *}$ \\
& Significance (two-tailed) & 0.177 & 0.000 & & 0.000 \\
& N & 188 & 188 & 188 & 188 \\
PSW & Pearson correlation & $0.261^{* *}$ & $-0.170^{*}$ & $0.733^{* *}$ & 1 \\
& Significance (two-tailed) & 0.000 & 0.020 & 0.000 & 188 \\
& N & 188 & 188 & 188 & 188 \\
& & & & & \\
\hline
\end{tabular}

Significance levels: * significant at the 0.05 level, ** significant at the o.o1 level (two-tailed).

significant differences in emotional attachment between the increasing and decreasing usage groups $(p=0.000, d=4.22)$ and between the decreasing group and the constant usage groups $(p=0.002, d=2.76)$ but no significant difference between the increasing and constant usage groups $\left(p=0.18_{4}\right.$, $d=1.46)$.

The results of the unrelated one-way ANOVA for a sense of belonging showed no significant difference between the sense of belonging scores for the three different usage groups; the $F$-value was just insignificant at $2.787(p=0.064)$ and no significant differences were flagged by the posthoc Bonferroni multiple comparisons. Further Pearson correlations reveal one positive association between frequency of use and sense of belonging but only for users of smartphones $(r=0.590, p=0.000)$.

The assumption of homogeneity of variance was also violated for perceptions of self-worth and therefore the Welch $F$-ratio has been utilised. There is a significant effect of technology usage on users' perceptions of self-worth, $F(2,97.23)=4.07, p=0.020$. A Games-Howell post-hoc analysis demonstrates significant differences in self-worth between the increasing usage and decreasing usage groups $(p=0.031, d=2.74)$ but not between the constant usage and decreasing usage groups $(p=0.190, d=1.89)$ or between the constant and increasing usage groups $(p=0.216, d=0.85)$.

\section{Emotional attachment}

The significant correlation between the emotional attachment score and frequency of use $(r=0.221, p=0.002)$ implies that the more the technology is used, the higher the emotional attachment towards the device. This was 
T A B L E 2. Descriptive statistics for frequency of use and outcome measures

\begin{tabular}{|c|c|c|c|}
\hline & Increasing usage & Constant usage & Decreasing usage \\
\hline \multicolumn{4}{|c|}{ Frequency of use: } \\
\hline $\mathrm{N}$ & 53 & 88 & 47 \\
\hline Mean & 63.45 & $47 \cdot 4^{1}$ & $17 \cdot 34$ \\
\hline SD & 42.57 & $4^{6.63}$ & $22.3^{6}$ \\
\hline $\mathrm{SE}$ & 5.85 & 4.97 & 3.26 \\
\hline \multicolumn{4}{|c|}{ Emotional attachment scale: } \\
\hline $\mathrm{N}$ & 53 & 88 & 47 \\
\hline Mean & 16.62 & 15.17 & $12.4^{1}$ \\
\hline SD & $4 \cdot 36$ & $5 \cdot 31$ & 3.94 \\
\hline SE & 0.60 & 0.57 & $0.5^{8}$ \\
\hline \multicolumn{4}{|c|}{ Sense of belonging scale: } \\
\hline $\mathrm{N}$ & 53 & 88 & 47 \\
\hline Mean & 25.60 & $27 \cdot 49$ & $25 \cdot 72$ \\
\hline SD & $4 \cdot 32$ & 4.86 & 5.62 \\
\hline SE & 0.79 & 0.55 & 0.79 \\
\hline \multicolumn{4}{|c|}{ Perceptions of self-worth scale: } \\
\hline $\mathrm{N}$ & 53 & 88 & 47 \\
\hline Mean & 28.68 & 27.83 & 25.94 \\
\hline SD & 2.38 & 3.62 & 6.86 \\
\hline SE & 0.33 & 0.39 & 1.00 \\
\hline
\end{tabular}

Notes: SD: standard deviation. SE: standard error.

explored further with an unrelated one-way ANOVA, which was significant, conveying that technology usage had a significant effect on emotional attachment towards an everyday device for older adults. The diary data will now be investigated to support this statistical revelation and comment on themes that have emerged.

From the qualitative data, it became apparent that the importance of a device to a user seemed to instil emotional attachment towards that technology. For instance, words such as want (40), need (25), needed (13), useful (1 1 ) and needs (five) emerged in the frequency word search, whereas negative words indicating a lack of importance were low, for example useless (six). It appeared that some users really needed their technology and through this importance, an emotional attachment to the device was formulated. One participant reported needing to use her e-reader to access e-mails whilst away from home:

Visiting my daughter in Liverpool for the weekend and having no internet connection I checked my emails on the Kindle. Very useful as an important one had arrived that needed a quick response. (Participant B, female, aged 67, married, owned e-reader for six months)

The same participant also described her e-reader as 'great', 'exciting', 'excellent', 'fantastic' and 'invaluable', which demonstrates a link between how important or invaluable a device is and the attachment 
towards it. Moreover, the same participant portrayed an emotional attachment to her e-reader as she 'regretted not having it [her hardback bookgroup book] on the Kindle so that [she] I could pop it in [her] my bag and read on the train' (Participant B). May, Garrett and Ballantyne (2010) support this observation as they report on the importance of scooters in older adult's lives; they enable freedom and independence, maintain friendships, help carry out daily errands and keep in touch with wider communities. 'The emotional, personal and physical importance of scooters in the lives of the older people in this study repeatedly emerged from the data' (May, Garrett and Ballantyne 2010: 1228) and through this dependence, the older adults establish an emotional relationship with their scooters.

The interactivity of the technology is another implied impact of emotional attachment towards technological devices for older adults. Heerink et al. (2008) discovered that the emotional attachment, especially enjoyment, towards a robot was dependent on how interactive the robot was with the participants. The diary data support this research by indicating more emotional attachment to technologies that are interactive or allow interaction with friends and relatives. For instance, words discovered in the frequency search denote a level of interaction with the devices: e-mail ( 115 ), play (23), message (19), Google (17) and internet (17). One participant, who used her iPad up to three times a day, indicates how interaction with and through her device can improve negative feelings and enhance positive emotions:

just checked and received some lovely joke e-mails from friend, feeling pretty fed up with re-wiring so really appreciated them. Sent a quick 'thank you'. (Participant M, female, aged 71 , widowed, owned tablet for six months)

An extremely noticeable connection between emotional attachment towards a device and interaction is the relationships that are upheld through technology despite the physical and geographical boundaries that can emerge in older age (Drennan et al. 2008). It is apparent from the diary data that interaction and hence emotional attachment towards a technology is often associated with personal relationships. For instance, photographs and images of family and friends hold a high importance with older adults and can impact on the attachment towards a device:

Shots of Granddaughter's Birthday visit, created a 'Fun Multiple Image' for the Family Album. (Participant J, female, aged 77, divorced, owned laptop for four months)

Consequently, the positive relationship between frequency of use and emotional attachment towards a device depends on the importance of the technology to the older adult, how interactive and enjoyable the device is to use and the relationships that are upheld through the connectivity of the technology. 


\section{Sense of belonging}

The strong Pearson correlation between a sense of belonging and perceptions of self-worth $(r=0.733, p=0.000)$ support the notion that if older people feel as if they belong within society, family and friends, then they are more likely to have higher perceptions of self-worth, which in turn leads to a reduction in depression (Krause 2005). The question remains whether technology has an influence on these factors. There was no significant correlation between sense of belonging and frequency of use and no significant effect of usage on sense of belonging, however, for highly communicative devices such as mobile phones, it appears that the usage of that device positively correlates with a sense of belonging $(r=0.590, p=$ o.ooo). This deduction is also supported by the literature on older people and mobile phone use; Mallenius, Rossi and Tuunainen (2007) argue that with technology older people often seek advice from relatives whilst also being influenced by the opinion of friends and family, especially children and grandchildren. In other words, using a technology increases social contact and is often a result of social influence, which impacts on general feelings of belonging (Karavidas, Lim and Katsikas 2005; Selwyn $2004)$.

The chosen measure of a sense of belonging (Hagerty and Patusky 1995) did not correlate with frequency of use, except for the mobile phone data, however, the literature and qualitative diary data champion technology use as improving older adults' social connections and sense of belonging. The frequency word search of the diary data identified words for family and friends such as people (38), son (23), friend (22), wife (18), contacts (15), nephew (13) and family (nine). The reported interaction with family and friends supports Mallenius, Rossi and Tuunainen's (2007) proposal that social influence strongly encourages technology usage for older

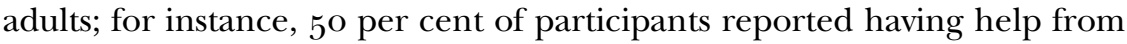
relatives and friends if they had problems with their devices. Some participants required help only occasionally whilst others were frequently in contact with people regarding the technical difficulties that they were experiencing. The following participant had help with her iPad from a large array of acquaintances:

Presumably I can still make appointments to get advice from our local Apple store, and if not I've got techie nephew, his mum, sister and her techie boyfriend to appeal to. (Participant S, female, aged 71, married, owned tablet for three months)

Interestingly, however, when it came to the acquisition of the technical device, very few participants reported either being encouraged to buy or being given a technology by friends or family, which is in contradiction to 
the discoveries of Selwyn's (2004) study on ICT use by older adults. Alternatively, participants demonstrated an independence of choice and desire to purchase and use their technologies for specific purposes:

Ordered iPad from Apple online. (Participant S, female, aged 71, married, owned tablet for three months)

I purchased the laptop to take to the MK [Milton Keynes] $\mathrm{U}_{3} \mathrm{~A}$ 'Fun with Photography' Group meetings, for 'Hands On' sessions and to give demonstrations of photo editing techniques. (Participant J, female, aged 77 , divorced, owned laptop for four months)

These discoveries may be due to when the data were collected. In 2004, technology was not as widely used as it is currently and many older people would be unfamiliar with devices, programmes, processes and the internet. Any data collected from older adults in the current environment do include more participants who used technology either in a professional or domestic context prior to retirement. Consequently, the majority will have previous experience with devices or processes similar to the ones they are reporting on in the present study (Nägle and Schmidt 2012; Olson et al. 2011 ). Although participants may have independently acquired their technology as opposed to receiving second-hand machines, technological presents and strong advice from relatives (Selwyn 2004), 50 per cent still relied on connections with friends and family to support the use of technology. It can therefore be reasoned that technology, even when it is causing problems, can enhance a feeling of belonging.

From the frequency word search it became apparent that the main function of the everyday devices was communication through e-mail, with e-mail or derivatives of featuring 115 times whilst other forms of communication such as Facebook only being mentioned 13 times. Consequently, the present data support Wagner, Hassanein and Head's (2010) observation that communication is the central function of technology use by older adults, which helps with social support and feelings of belonging. An interesting observation is the divide between social media and e-mail use, with the majority of participants strongly favouring the latter (Jones and Fox 2009), whilst social media such as Facebook received mixed and even negative reviews:

Matthew has now transferred my photo to Facebook, I have gleaned a little more information about how people use the facility and how to post photo to e-mail files. Spent fifteen minutes looking at Facebook information but continue of the opinion that it's not for me. (Participant M, female, aged 71, widowed, owned tablet for six months)

Several other things are really too small to be of use; icons are there I don't need, and I'm not into Facebook or Twitter. (Participant I, male, aged 83, married, owned smartphone for one month) 
These observations are similar to discussions raised by previous academic research; for instance, Cornejo, Favela and Tentori (2010) conclude that older adults are less interested in social media because they are less technically inclined whilst Chakraborty, Vishik and Rao (2013) and Xie et al. (2012) suggest that privacy is the largest issue. This study merely presents a lack of interest and desire as other forms of communication, for instance e-mails, are sufficient. Xie et al. (2012) present educational strategies to target negative and apathetic perceptions of social media, which could improve usage of this type of communication by people over the age of 65 . The contention with this, however, is would the use of social media actually improve the quality of life of older adults? Currently, many participants appear content with communication through e-mail and over the phone, which maintains levels of social belonging; as indicated by the strong correlation between usage and sense of belonging for the most communicative device (smartphone) but not for the other devices (tablet, laptop and e-reader).

The final observation involving sense of belonging related to uses of technology include the group mentality that certain devices produce. For instance, there is this sense of Apple users in contention with PC [personal computer] users and Kindle users in contention with non-Kindle users: 62.5 per cent of the participants in the diary study noted a group mentality towards their device; for instance, two participants were multiple Apple technology owners, one very much stated herself as part of the PC contingency whilst another two participants discussed a rivalry between Kindle users and non-Kindle users amongst their friends:

G and K were discussing Kindles. G said: 'I don't think anything compares to the feel of a page turning in your hands.' K agreed; and they looked at me as though I should leap to the defence of my Kindle. I didn't take any notice - I was getting the lunch. It reminded me of when I was a vegetarian, and people expected you always to be defending vegetarianism. Yes, it's nice to feel a page turning ... but not that nice-nicer to have the promise of another book always there to be read. (Participant G, female, aged 77, unmarried, owned e-reader for four months)

This type of technology use influenced by group camaraderie has been observed previously in research on scooter use (May, Garrett and Ballantyne 2010). In this study, participants formed scooter support groups that met regularly, held outings and travelled together. This type of loyalty towards a technology or brand is called social identification (Kim, Han and Park 2001) and involves social belonging towards particular groups or organisations. Several studies on mobile phone adoption have also indicated the importance of brand loyalty and social identification of post-purchase usage (Kim, Han and Park 2001; Lee 2011 ) but argue for more studies focusing on the influence of brand loyalty on post-adoption behaviours. 
Although a sense of belonging did not directly relate to frequency of use in the statistical analysis, there is evidence from the qualitative analysis that participants' use of technology enhanced their social connections and communication with friends and relatives, especially when poor health and geographical remoteness can limit face-to-face interaction. The favoured method of communication was e-mail, whereas social media such as Facebook and Twitter were perceived to be uninteresting. There was also a feeling of belonging emerging from the group camaraderie that certain technology users gained from using certain devices such as Apple devices or Kindles, which highlights the importance of brand within the technology industry.

\section{Perceptions of self-worth}

The significant correlation between perceptions of self-worth and frequency of use $(r=0.261, p=0.000)$ implies that the more the technology is used, the higher the older adults' self-esteem. This was explored further with an unrelated one-way ANOVA, which was significant, conveying that rate of technology use had a significant effect on participants' perceptions of self-worth. Previous research suggested that this is due to the communicative nature of everyday devices, for instance Cattan, Kime and Bagnall (2011) discovered that the use of a telephone to talk to friends and family alleviated older people's loneliness and improved self-esteem and confidence levels amongst the participants. Additionally, Khvorostianov, Elias and Nimrod (2012) discovered that for socially isolated older immigrants, the internet helps maintain social networks, which improves the psychological wellbeing and self-worth of their participants. Internet use, specifically social media use, can be positively influenced by the experience that users possess and the autonomy of use alongside the user's gender, race and ethnicity (Hargittai 2008). The following section further explores the self-efficacy of device and internet use but in relation to the experiences of older adults.

An additional connection between self-worth and technology use, other than communication, is the confidence produced from a technology that is easy to use. Arning and Ziefle (2007) discovered a strong relationship between technical confidence and performance for their older participants, whilst Hargittai (2008) demonstrates that more experience increases internet and social media usage. In other words, how easy a device is to use directly effects the confidence of the older user (Arning and Ziefle 2007) and how often that technology is used (Hargittai 2008). This may explain why the e-reader, which has little communicative quality other than checking e-mails, has a high correlation between self-worth and usage $(r=0.472, p$ $=0.000$ ). The e-reader is generally user friendly and with fewer functions, 


\section{Carolyn Wilson}

it is easy to use whilst fulfilling the user's needs. The statistics reveal that 87.5 per cent of e-reader users in this study agree or strongly agree that their ereader is easy to use; this is in comparison to 59 per cent for laptop users, 79.3 per cent for iPad users and 85.8 per cent for smartphone users. Consequently, use of the e-reader enhances confidence levels and selfworth as participants relate to its user-friendly design.

The diary data seem to support the two themes that have emerged from the literature and the survey data; firstly, that ease of use impacts upon feelings of self-worth and, secondly, that communication through technology improves social belonging which in turn impacts perceptions of selfworth. In reference to ease-of-use, it appears that if participants find a technology easy to use or if they manage to decipher how something works, they often have feelings of pride and achievement. For instance, the frequency word search has identified words such as used (45), found (43), worked (17) and able (15), which often refer to the accomplishment of understanding and using a technology:

Downloaded BBC iPlayer Radio app onto iJack, and it worked! (Participant S, female, aged 71, married, owned tablet for three months)

I tried this OCR [optical character recognition] app on a paragraph from a book: no trouble, it worked. You snap a picture, send it to yourself by e-mail, open it up and there's both picture and transcript; the picture helps to corroborate the correct transcription. (Participant I, male, aged 83, married, owned smartphone for one month)

The sense of achievement that participants feel when correctly deciphering their technology improves technological confidence and self-worth. Previous research on assistive technology has discovered a similar trend, with participants who use the devices successfully reporting a significant improvement in accomplishment scores (Mortenson et al. 2012). On the flip side, if a technology proves too challenging, this may negatively impact on the users' technical confidence and perceptions of self-worth. The diary data indicate that this is the case; for instance, participants who experienced technical difficulties often question themselves and their own abilities:

Advertising e-mail from Holland and Barrett, reminded me to check if I have collected any points on my reward card but it still appears, despite purchases I've not been awarded any. This is where I find on-line activity frustrating ... 'is it me doing something wrong?' (Participant $\mathrm{M}$, female, aged 71 , widowed, owned tablet for six months)

Oddly enough, Apple are a 'Which?' best buy, and $\mathrm{O}_{2}$ are a members' favourite. Is it me? (Participant I, male, aged 83, married, owned smartphone for one month)

As Arning and Ziefle (2007) argue, technical confidence is closely linked to performance for the older adult and so if a device provides technical 
difficulties, the older adult, as evidenced above, begins to question their own worth. The following quote demonstrates the extent to which technical problems can affect the older user, forcing self-blame and belittling:

Back to Home. Then I remembered I could slide to the left: and there were all five of my apps! Dumb Sandra! (Participant S, female, aged 71, married, owned tablet for three months)

These results have important impacts on policy makers encouraging technology use by people over the age of 65 (Eastman and Iyer 2005). A difficult technology could have adverse impacts on older adult's perceptions of self-worth whilst an easy to use technology can improve life satisfaction and lower computer anxiety (Karavidas, Lim and Katsikas 2005). Consequently, if technology use is being introduced to the aforementioned population, it should be stylised for the consumer so that it is easy to use or introduced with a learning programme so that the consumer develops a technology confidence. For instance, the introduction of a telephone befriending scheme (Cattan, Kime and Bagnall 2011) or encouraging older adults to use the internet to connect with friends and family (Eastman and Iyer 2005; Khvorostianov, Elias and Nimrod 2012; Mitchell et al. 2011 ) are successful examples.

The use of technology to connect with acquaintances is the second theme that impacts upon the relationship between self-worth and technology use. The strong correlation between sense of belonging and perceptions of selfworth $(r=0.733, p=0.000)$ reveal that when somebody feels as if they belong within their environment and society this positively impacts upon their feelings of self-worth and general life satisfaction (Cattan, Kime and Bagnall 2011; Karavidas, Lim and Katsikas 2005; Khorostianov, Elias and Nimrod 2012). The diary data indicate that this feeling of belonging can emerge from the use of technology and as such positively impact further uses and feelings of self-worth. Images, stories, moments and information can be shared across space in a matter of moments; a function that is imperative for people whose health problems can affect mobility and participation in social and leisure activities (Drennan et al. 2008; Scherger, Nazroo and Higgs 2010):

The other day a recent carer in my wife's nursing home took it into her head to take my wife out to the local park in a wheelchair, for the first time out for over two years. I was delighted. She helped to pick blackberries, and the carer gave her an ice cream in a cornet; she took a picture on her iPhone of both of them. I asked her to email it to me ... I have forwarded that iPhone photograph I told you about of herself with Jane to various people that knew her. (Participant I, male, aged 83, married, owned smartphone for one month)

This vital function of technology is highly important to the participants in the present study; all of whom shared jokes, stories, photographs and 


\section{Carolyn Wilson}

correspondence over e-mail, whatever device they were using (tablet, ereader, laptop or smartphone), which often became a lifeline of support, relief and enjoyment. There were, of course, technical difficulties for most participants $(87.5$ per cent), however, the communication that devices provided often outweighed the user problems, providing a sense of belonging and self-worth within a world that, without technology, could be restrictive and lonely (Kirkevold et al. 2012). The following quote is from a participant who had great technical difficulties with her iPad; she found it challenging and poorly designed yet she still admits that she will use it for communicative purposes and keeping up-to-date with worldly and local information through reading the news and watching television:

Overall, I find iJack a fiddly, time-wasting device that's not nearly as intuitively designed as our PC - but perhaps that's because I'm used to the PC's foibles. iJack will still serve well for its main purpose: to take travelling to keep abreast of bank and credit card accounts, pay bills, check email and listen to news in English. And take pictures. And watch missed TV shows on iPlayer and ITV player. (Participant $\mathrm{S}$, female, aged 71, married, owned tablet for three months)

\section{Is it love or loneliness?}

An interesting relationship that emerged from the survey data was a negative association between sense of belonging and emotional attachment towards a device $(r=-0.376, p=0.000)$. In other words, the more emotionally attached a participant was to their technology, the lower their feelings of belonging. This relationship is fascinating as it was not predicted by any literature on older adults and technology use. In contrast, the negative association is usually found amongst adolescents and young adults with a dependence on video games (Schmit et al. 2011; Wei et al. 2012). Schmit et al. (2011) used the same scales as the present study to measure sense of belonging (Hagerty and Patusky 1995) and perceptions of self-worth (Rosenberg 1989) and discovered that the more participants were dependent on their technologies, in this instance video games, the lower their feelings of belonging and perceptions of self-worth. The present study seems to indicate similar results but for older adults' emotional attachment to their portable interactive devices and a sense of belonging. Further investigation would be required to support this finding, but it could have important implications on public policy makers striving to introduce older people to technology and encouraging them to go online (Eastman and Iyer 2005). For instance, over-dependence could have the opposite effect to what policy makers were hoping and actually reduce the feelings of belonging that older adults have. 


\section{Conclusion}

The qualitative and quantitative exploration of older adult technology use has revealed that the more a device is used, the more emotionally attached the user becomes. Event-based diary data reveal that emotional attachment is stronger towards devices that are either interactive or highly important to the participants, which has significant implications for innovators and developers of technology for older adults. The design of a device should therefore provide a level of interaction, whether this be from a social connection or the device itself. Furthermore, it should possess the utility to be useful and invaluable in the everyday, which increases the older adult's attachment to the technology and likelihood of buying accessories and upgrades.

The question therefore remains, can this usage and emotional attachment towards a device improve older adults' sense of belonging and perceptions of self-worth in an attempt to reduce loneliness? Statistically, a sense of belonging was not influenced by technology use, except for the mobile phone users. There was qualitative evidence, however, that technology encouraged older adults to communicate with friends and relatives, especially through e-mails. This communication and how easy a device was to decipher had a positive impact on older adults' perceptions of self-worth, which did correlate positively with frequency of use. Alternatively, if participants found technology difficult to use, this had a detrimental effect on self-esteem. Since the economic crisis in 2007-8, further public services are being moved online; hence for these to be introduced successfully to older adults by policy makers and non-profit organisations, devices, websites and software should be easy to use and include clear training and instructions.

In summation, there was a positive relationship between frequency of use and perceptions of self-worth but further research is required to validate a relationship between a sense of belonging and frequency of technology use; to see if the technology can actually impact a feeling of belonging and alleviate loneliness. Moreover, considering that highly communicative devices such as smartphones did reveal a positive correlation between a sense of belonging and technology use, it would be of value for academic research in this area to explore the impact of communicative devices on the loneliness of older adults.

One unexpected yet important relationship that emerged between the independent variables was a significant negative correlation between emotional attachment and social belonging. For instance, the more the participant was emotionally attached towards their technology, the less socially involved they were in their surroundings. This relationship has been observed before in adolescents who are dependent upon video games (Schmit et al. 2011; Wei et al. 
2012 ) but has yet to be stressed within the literature of everyday digital devices and the scholarship of older adult technology use. As a result, further investigation into the two variables, emotional attachment and a sense of belonging, is required to observe if this relationship reoccurs for older adults using everyday technologies and why it occurs; it could be connected to specific functions the device possesses or a particular type of user.

Moreover, research projects, policy and non-profit organisations intending to influence technology use in the older adult community should be aware that there may be a delicate balance between a healthy usage creating connections over geographical boundaries and an over-dependence on a technology, which could in fact reduce feelings of belonging and even perceptions of self-worth. If future research deduces a similar relationship between the two variables, before technology is introduced into people's lives, the instigators should be conscious of this possible negative effect of overuse and dependence. For instance, as with technology in health care, the system or device should only be introduced as an enhancement to a previous service, not as a replacement for social interaction.

Methodologically, there are limitations to the present study as a small sample size of $3^{2}$ has limited the quantitative data that were collated. Although the Pearson correlations were calculated using the aggregate data from 188 responses across the six-month time period, these calculations alongside the unrelated one-way ANOVAs would only be enhanced by a larger sample size. Moreover, participants were recruited from $\mathrm{U}_{3} \mathrm{~A}$ organisations and although education levels varied from no qualifications to postgraduate qualifications, by joining a $\mathrm{U}_{3} \mathrm{~A}$ all participants have demonstrated an interest in learning, which may have impacted on their usage of technologies. Finally, the sample included an uneven spread of 21 females and 11 males. Considering that social media use can be influenced by gender (Hargittai 2008), it would be beneficial to even out this inequality and the education levels by increasing the sample size to incorporate a wider selection of older adults.

\section{Acknowledgement}

I would like to acknowledge Professor Mike Nicholson and Dr Sarah Xiao for supporting and inspiring me in this research. I would also like to thank the members of the $\mathrm{U}_{3} \mathrm{~A}$ organisations that participated in the study. Ethical approval was granted by Durham University Business School as per the requirements of the PhD programme. 


\section{References}

Ainsworth, M. S. 1979. Infant-mother attachment. American Psychologist, 34, 10, 9327 .

Arning, K. and Ziefle, M. 2007. Understanding age differences in PDA acceptance and performance. Computers in Human Behavior, 23, 6, $2904-27$.

Arning, K. and Ziefle, M. 20og. Effects of age, cognitive, and personal factors on PDA menu navigation performance. Behaviour and Information Technology, 28, 3, 25168.

Ball, D. A. and Tasaki, L. H. 1992. The role and measurement of attachment in consumer behavior. Journal of Consumer Psychology, 1, 2, $155^{-72 .}$

Ballantyne, A., Trenwith, L., Zubrinich, S. and Corlis, M. 2010. 'I feel less lonely': what older people say about participating in a social networking website. Quality in Ageing and Older Adults, 11, 3, 25-35.

Berkowsky, R. W., Cotton, S. R., Yost, E. A. and Winstead, V. P. 2013. Attitudes towards and limitations to ICT use in assisted and independent living communities: findings from a specially-designed technological intervention. Educational Gerontology, 39, $11,797-811$.

Bolger, N., Davis, A. and Rafaeli, E. 2003. Diary methods: capturing life as it is lived. Annual Review of Psychology, 54, 1, 579-616.

Bowlby, J. 1969. Attachment and Loss. Volume 3, Basic Books, New York.

Buse, C.E. 2010. E-scaping the ageing body? Computer technologies and embodiment in later life. Ageing $\mathcal{E} \mathcal{F}$ Society, 3o, 6, 987-1009.

Carroll, B. A. and Ahuvia, A. C. 2006. Some antecedents and outcomes of brand love. Marketing Letters, 17, 2, 79-89.

Cattan, M., Kime, N. and Bagnall, A. M. 2011. The use of telephone befriending in low level support for socially isolated older people - an evaluation. Health and Social Care in the Community, 19, 2, 198-206.

Chakraborty, R., Vishik, C. and Rao, H. R. 2013. Privacy preserving actions of older adults on social media: exploring the behavior of opting out of information sharing. Decision Support Systems, 55, 4, 948-56.

Chevalier, A., Dommes, A. and Martins, D. 2013. The effects of ageing and website ergonomic quality on internet information searching. Ageing $\mathcal{E}$ Society, 33, 6, 1009-35.

Cohen, J. 1960. A coefficient of agreement for nominal scales. Educational and Psychological Measurement, 2o, 1, 37-46.

Cohen-Mansfield, J. and Perach, R. 2015. Interventions for alleviating loneliness among older persons: a critical review. American Journal of Health Promotion, 29, 3, $109-25$.

Cornejo, R., Favela, J. and Tentori, M. 2010. Ambient displays for integrating older adults into social networking sites. Collaboration and Technology, Lecture Notes in Computer Science, 6257, $321-36$.

Cornwell, J., Levenson, R., Sonola, L. and Poteliakhoff, E. 201 2. Continuity of Care for Older Hospital Patients: A Call for Action. King's Fund, London.

Drennan, J., Treacy, M., Butler, M., Byrne, A., Fealy, G., Frazer, K. and Irving, K. 2008. The experience of social and emotional loneliness among older people in Ireland. Ageing $\mathcal{E}$ Society, 28, 8, $11113^{-32}$.

Dykstra, P. A., Van Tilburg, T. G. and de Jong Gierveld, J. 2005. Changes in older adult loneliness results from a seven-year longitudinal study. Research on Aging, $\mathbf{2 7}, 6,725^{-47}$. 


\section{Carolyn Wilson}

Eastman, J. K. and Iyer, R. 2005. The impact of cognitive age on Internet use of the elderly: an introduction to the public policy implications. International Journal of Consumer Studies, 29, 2, $125^{-36}$.

Flynn, K. E., Smith, M. A. and Freese, J. 2006. When do older adults turn to the internet for health information? Findings from the Wisconsin Longitudinal Study. Journal of General Internal Medicine, 21, 1 2, 1 295-301.

Foxall, G. R. 1995. Science and interpretation in consumer research: a radical behaviourist perspective. European Journal of Marketing, 29, 9, 3-99.

Foxall, G. R. 1998. Radical behaviourist interpretation: generating and evaluating an account of consumer behaviour. The Behavior Analyst, 2 1, 2, 321-54.

Gaymu, J. and Springer, S. 2010. Living conditions and life satisfaction of older Europeans living alone: a gender and cross-country analysis. Ageing $\mathcal{E}$ Society, 3o, $7,1153-75$.

Hagerty, B. M. and Patusky, K. 1995. Developing a measure of sense of belonging. Nursing Research, 44, 1, 9-13.

Hardill, I. and Olphert, C. W. 201 2. Staying connected: exploring mobile phone use amongst older adults in the UK. Geoforum, 43, 6, 1306-12.

Hargittai, E. 2008. Whose space? Differences among users and non-users of social network sites. Journal of Computer-mediated Communication, 13, 1, 276-97.

Hedman, A., Nygård, L., Almkvist, O. and Kottorp, A. 2013. Patterns of functioning in older adults with mild cognitive impairment: a two-year study focusing on everyday technology use. Aging and Mental Health, 17, 6, 679-88.

Heerink, M., Krose, B., Evers, V. and Wielinga, B. 2008. The influence of social presence on acceptance of a companion robot by older people. Journal of Physical Agents, 2, 2, 33-40.

Heylen, L. 2010. The older, the lonelier? Risk factors for social loneliness in old age. Ageing $\mathcal{E}^{2}$ Society, 3o, 7, $1177-96$.

Hirsch, T., Forlizzi, J., Hyder, E., Goetz, J., Kurtz, C. and Stroback, J. 20oo. The ELDer project: social, emotional, and environmental factors in the design of eldercare technologies. In Thomas, J. (ed.), Proceedings on the 2000 Conference on Universal Usability. ACM, New York, 72-9.

Imison, C., Thompson, J. and Poteliakhoff, E. 201 2. Older People and Emergency Bed Use. Exploring Variation. King's Fund, London.

Joe, J. and Demiris, G. 2013. Older adults and mobile phones for health: a review. Journal of Biomedical Informatics, 46, 5, 947-54.

Jones, S. and Fox, S. 2009. Generations Online in 2009. Pew Internet and American Life Project, Washington DC.

Jylha, M. 2004. Old age and loneliness: cross-sectional and longitudinal analyses in the Tampere Longitudinal Study on Aging. Canadian Journal on Aging, 23, 2, $157-68$.

Karavidas, M., Lim, N. K. and Katsikas, S. L. 2005. The effects of computers on older adult users. Computers in Human Behavior, 21, 5, 697-711.

Kharicha, K., Iliffe, S., Harari, D., Swift, C., Gillmann, G. and Stuck, A. E. 2007. Health risk appraisal in older people 1: are older people living alone an 'atrisk'group? British Journal of General Practice, 57, 537, 271-6.

Khvorostianov, N., Elias, N. and Nimrod, G. 201 2. 'Without it I am nothing': the internet in the lives of older immigrants. New Media and Society, 14, 4, 583-99.

Kim, C. K., Han, D. and Park, S. B. 2001. The effect of brand personality and brand identification on brand loyalty: applying the theory of social identification. Japanese Psychological Research, 43, 4, 195-206. 
Kirkevold, M., Moyle, W., Wilkinson, C., Meyer, J. and Hauge, S. 201 2. Facing the challenge of adapting to a life 'alone' in old age: the influence of losses. Journal of Advanced Nursing, 69, 2, 394-403.

Krause, N. 2005. Traumatic events and meaning in life: exploring variations in three age cohorts. Ageing E् Society, 25, 4, 501-24.

Lam, J. C. and Lee, M. K. 20o6. Digital inclusiveness - longitudinal study of Internet adoption by older adults. Journal of Management Information Systems, 22, 4, 1 77-206.

Landis, J. R. and Koch, G. G. 1977. The measurement of observer agreement for categorical data. Biometrics, 33, 1, 159-74.

Lee, Y. C. 2011 . m-Brand loyalty and post-adoption variations for the mobile data services: gender differences. Computers in Human Behavior, 27, 6, 2364-71.

Lee, Y. S. 2007. Older adults' user experiences with mobile phones: identification of user clusters and user requirements. Doctoral dissertation, Virginia Polytechnic Institute and State University, Blacksburg, Virginia.

Mallenius, S., Rossi, M. and Tuunainen, V. K. 2007. Factors affecting the adoption and use of mobile devices and services by elderly people - results from a pilot study. Paper presented at the 6th Annual Global Mobility Roundtable, 31 May to 2 June, Los Angeles.

Mata, R. and Nunes, L. 2010. When less is enough: cognitive aging, information search, and decision quality in consumer choice. Psychology and Aging, 25, 2, 289-98.

May, E., Garrett, R. and Ballantyne, A. 2010. Being mobile: electric mobility-scooters and their use by older people. Ageing E Society, 3o, 7, $1219-37$.

Millward, L. J. 2006. Focus groups. In Breakwell, G. M., Hammond, S., Fife-Schaw, S. and Chris, J. A. (eds), Research Methods in Psychology. Third edition, Sage, London.

Mitchell, M. E., Lebow, J. R., Uribe, R., Grathouse, H. and Shoger, W. 2011 . Internet use, happiness, social support and introversion: a more fine grained analysis of person variables and internet activity. Computers in Human Behavior, 27, 5, 1857-61.

Morgan, P. 2010. Towards a developmental theory of place attachment. Journal of Environmental Psychology, 3o, 1, 1 1-22.

Mortenson, W. B., Demers, L., Fuhrer, M. J., Jutai, J. W., Lenker, J. and DeRuyter, F. 2012. How assistive technology use by individuals with disabilities impacts their caregivers: a systematic review of the research evidence. American Journal of Physical Medicine and Rehabilitation, 91, $11,984-98$.

Nägle, S. and Schmidt, L. 2012. Computer acceptance of older adults. Work: A Journal of Prevention, Assessment and Rehabilitation, 41, Supplement 1, 3541-8.

Office for National Statistics 2012. 2011 Census - Population and Household Estimates for England and Wales, March 2011 . Available online at http://www.ons.gov.uk/ ons/rel/census/201 1-census/population-and-household-estimates-for-englandand-wales/stb-e-w.html [Accessed 22 August 2012]

Olson, K. E., O'Brien, M. A., Rogers, W. A. and Charness, N. 201 1. Diffusion of technology: frequency of use for younger and older adults. Ageing International, 36, 1, $123-45$.

Poland, M. P., Nugent, C. D., Wang, H. and Chen, L. 201 1. Pure random search for ambient sensor distribution optimisation in a smart home environment. Technology and Health Care, 19, 3, 137-6o.

Porock, D., Clissett, P., Harwood, R. H. and Gladman, J. R. 2015 . Disruption, control and coping: responses of and to the person with dementia in hospital. Ageing $\mathcal{E}^{\circ}$ Society, 35, 1, 37-63.

Rosenberg, M. 1989. Society and the Adolescent Self-image. Wesleyan University Press, Middleton, Connecticut. 
Rosenthal, R. L. 2008. Older computer-literate women: their motivations, obstacles and paths to success. Educational Gerontology, 34, 7, 610-26.

Royal College of Psychiatrists 2005. Who Cares Wins. Royal College of Psychiatrists, London.

Savikko, N., Routasalo, P., Tilvis, R. S., Strandberg, T.E. and Pitkälä, K. H. 2005. Predictors and subjective causes of loneliness in an aged population. Archives of Gerontology and Geriatrics, 41, 3, 223-33.

Scherger, S., Nazroo, J. and Higgs, P. 2010. Leisure activities and retirement: do structures of inequality change in old age? Ageing $\mathcal{E}^{\circ}$ Society, 31, 1, 146-72.

Schmit, S., Chauchard, E., Chabrol, H. and Sejourne, N. 2011. Evaluation of the characteristics of addiction to online video games among adolescents and young adults. L'Encephale, 37, 3, 21 7-23. (In French)

Selwyn, N. 2004. The information aged: a qualitative study of older adults' use of information and communications technology. Journal of Aging Studies, 18, 4, $369-84$.

Steed, L., Boldy, D., Grenade, L. and Iredell, H. 2007. The demographics of loneliness among older people in Perth, Western Australia. Australasian Journal on Ageing, 26, 2, 81-6.

Sum, S., Mathews, R. M., Hughes, I. and Campbell, A. 2008. Internet use and loneliness in older adults. CyberPsychology and Behavior, 11, 2, 208-11.

Tadd, W., Hillman, A., Calnan, S., Calnan, M., Bayer, T. and Read, S. 201 1. Dignity in practice: an exploration of the care of older adults in acute NHS Trusts. NIHR Service Delivery and Organisation Programme, Project o8/1819/218, NETSCC - SDO, Southampton, UK.

Thayer, S. E. and Ray, S. 20o6. Online communication preferences across age, gender, and duration of Internet use. CyberPsychology and Behavior, 9, 4, 432-40.

Van Beljouw, I. M.J., Van Exel, E., de Jong Gierveld, J., Comijs, H., Heerings, M., Stek, M. L. and van Marwijk, H. W. J. 2014 . 'Being all alone makes me sad': loneliness in older adults with depressive symptoms. International Psychogeriatrics, 26, 9, $154^{1-51 .}$

Victor, C. R. and Bowling, A. 201 2. A longitudinal analysis of loneliness among older people in Great Britain. Journal of Psychology: Interdisciplinary and Applied, 146, 3, 313-31.

Victor, C. R., Scambler, S. J., Bowling, A. N. N. and Bond, J. 2005. The prevalence of, and risk factors for, loneliness in later life: a survey of older people in Great Britain. Ageing E Society, 25, 3, 357-75.

Vincent, J. 2006. Emotional attachment and mobile phones. Knowledge, Technology and Policy, 19, 1, 39-44.

Vlachos, P. A., Theotokis, A., Pramatari, K. and Vrechopoulos, A. 2010. Consumerretailer emotional attachment: some antecedents and the moderating role of attachment anxiety. European Journal of Marketing, 44, 9/10, 1478-99.

Wada, K. and Shibata, T. 2007. Living with seal robots; its sociopsychological and physiological influences on the elderly at a care house. IEEE Transactions on Robotics, 23, 5, 972-80.

Wagner, N., Hassanein, K. and Head, M. 2010. Computer use by older adults: a multi-disciplinary review. Computers in Human Behavior, 26, $5,870-82$.

Wei, H. T., Chen, M. H., Huang, P. C. and Bai, Y. M. 201 2. The association between online gaming, social phobia, and depression: an internet survey. BMC Psychiatry, 12, 1,92 .

Weiss, R. S. 1973. Loneliness: The Experience of Emotional and Social Isolation. MIT Press, Cambridge, Massachusetts. 
Wheeler, L. and Reis, H. T. 1991. Self-recording of everyday life events: origins, types, and uses. Journal of Personality, 59, 3, 339-54.

Wild, K., Boise, L., Lundell, J. and Foucek, A. 2008. Unobtrusive in-home monitoring of cognitive and physical health: reactions and perceptions of older adults. Journal of Applied Gerontology, 27, 2, 181-200.

Xie, B., Watkins, I., Golbeck, J. and Huang, M. 201 2. Understanding and changing older adults' perceptions and learning of social media. Educational Gerontology, $\mathbf{3}^{\mathbf{8}}$, 4, 282-96.

Yim, C. K., Tse, D. K. and Chan, K. W. 2008. Strengthening customer loyalty through intimacy and passion: roles of customer-firm affection and customer-staff relationships in services. Journal of Marketing Research, 45, 6, 741-56.

Zarantonello, L. and Luomala, H. T. 2011 . Dear Mr Chocolate: constructing a typology of contextualized chocolate consumption experiences through qualitative diary research. Qualitative Market Research: An International Journal, 14, 1, 55-82.

\section{Accepted 7 December 20I 6; first published online 20 March 2017}

Address for correspondence:

Carolyn Wilson, Durham University Business School, Durham University, Mill Hill Lane, Durham DH1 ${ }_{3} \mathrm{LB}, \mathrm{UK}$

E-mail: c.l.wilson@durham.ac.uk 